\title{
RECESSION AND RECOVERY: A STATE AND REGIONAL ANALYSIS
}

\author{
John E. Connaughton and Ronald A Madsen*
}

The 1981-1982 recession was the most serious downturn for the United States economy since the 1930 s. Some state economies were more severely affected than others. The strength of the recovery and expansion following the recession has also varied from state to state. The purpose of this paper is first, to measure the relative severity of the recession for each state and second, to determine the strength of the ensuing recovery and expansion for each state. Although this information is potentially important to state and regional planners, it is not currently available.

The two most widely used sources of state performance levels present problems in measuring variations in a state's short run output. The State Personal Income Series, maintained by the Bureau of Economic Analysis (BEA), produces measures that ignore income received by the government, business, and foreign sectors and include transfer payments made to households. Because of the omissions and inclusion the series does not adequately reflect the cyclical performance of a state's economy. The Total Employment Series, also produced by the BEA, monitors employment levels rather than output levels of the state economies. While employment and output levels are related, changes in labor productivity and non-labor factors of production are not adequately reflected in the employment series. The problems inherent in both the personal income series and employment series leads us to the calculation of an alternative measure of short run state economic performance.

To measure the short-run performance of state economies it was necessary to calculate a measure called Gross State Product (GSP) on a quarterly basis. GSP is defined as the market value of all final goods and services produced by a state's economy in the designated time period. This measure is most clearly analogous to Gross Domestic Product (GDP) but can also be viewed as comparable to Gross National Product (GNP) ${ }^{1}$ The difference between GDP and GNP is stable in the short run and varies

\footnotetext{
* Authors are Associate Professors of Economics at the University of North Carolina at Charlotte.
}

only slightly in the long run. As the major purpose of this paper is short run cyclical analysis, the GNP-GDP difference is not of concern. Additionally, the summation of all GSPs (including Washington, DC's) would differ from GNP in the same manner as GDP would differ from GNP (specifically, the net inflow of labor and property incomes from abroad would not be included).

The technique used in this paper to calculate GSP for all 50 states is adapted from the method developed by Kendrick and Jaycox (1965). ${ }^{2}$ The major adjustment involves the calculation of GSP on a quarterly rather than annual basis. Annul GSP does not provide a good measure of variation over the business cycle because annual series have a smoothing effect on economic data. The GSP measures are calculated utilizing sector specific earnings data provided by the BEA. The exact procedure for calculating quarterly GSP is presented in Appendix I.

Seasonally adjusted, annualized levels of GSP were calculated for each state for each quarter between 1969-I and 1984-III by the techniques outlined in Appendix I. Based on these results, a set of four index values was calculated for each state: two to measure the relative impact of the 1981-1982 recession, and two to measure the strength of the subsequent recovery. The first of these index values, Index $A$, represents the maximum percentage decline in real GSP for each state versus the pre-recession level of real GSP in that state.

For each state a second index, Index B, was calculated to measure a different aspect of the severity of the 1981-1982 recession. This index measures, in percentage terms, the maximum loss in real GSP of each state versus the "anticipated" level of real GSP if the recession had not occurred. This index thus required the calculation of a long-term annual real growth rate (LTRGR) in GSP for each state and was based on the real GSP values between 1969-I and the pre-recession quarter. This measure was calculated using the longest period of time for which comparable data was available and is judged to provide the best measure of future state average growth. This judgement is based 
on the estimating period including several complete business cycles as well as the most current information available, and should be viewed as a conservative measure of long-term growth. This LTRGR was then applied to the pre-recession level of real GSP for each state to generate projected quarterly estimates termed "anticipated" real GSP. These values represent an estimate of what the state economy would have produced had the 1981-1982 recession not occurred. Index $B$ then measures the maximum loss in real GSP for each state versus that state's anticipated non-recession level of real GSP. This index may show a different picture of the relative severity of the recession between the states, since some states with low values of Index A may have large values of Index $B$ because of large long-term real growth rates (LTRGR).

Diagram 1 provides a summary of the approach used to calculate each index. The base level of real GSP is taken from the last prerecession quarter for that state. ${ }^{3}$ Thus, path $\mathrm{X}$ on the diagram ( 100 percent) is a pre-recession reference level for each state. The actual level of real GSP as a percentage of the base level real GSP is labeled $Y$ on the diagram and the maximum distance between $X$ and $Y$ yields Index A. (For those states which experienced no drop in real GSP, no value for Index $A$ is reported.) Path $\mathrm{Z}$ represents, in percentage terms, the anticipated non-recession level of real GSP for each state, and Index B was calculated at the point of maximum distance between paths $Y$ and $Z$. It is possible, even likely, Index A and Index B will be calculated in the same quarter, but the diagram shows them occurring in different quarters.

In addition to Index $A$ and Index $B$, two other index values were calculated for each state to measure the strength of the recovery as of 1984-III, the last period for which complete data were available. Index $\mathbf{C}$ measures the difference between path $\mathrm{Y}$ and path $\mathrm{X}$ in 1984-III. Thus, a positive value for this index will provide an estimate of the expansion in the annualized level of state output, in percentage terms, versus the pre-recession level. A negative value for this index will indicate that as of 1984-III, the state's economy had not yet attained its pre-recession output level.

The final index, Index $D$, measures the difference between 1984-III real GSP, as a percentage of the pre-recession level of real GSP, and the anticipated level of real GSP for 1984-III, as a percentage of the pre-recession level of real GSP. The calculation of the anticipated level of real GSP utilizes the same LTRGR calculated in the construction of Index $B$ and projects the pre-recession level of

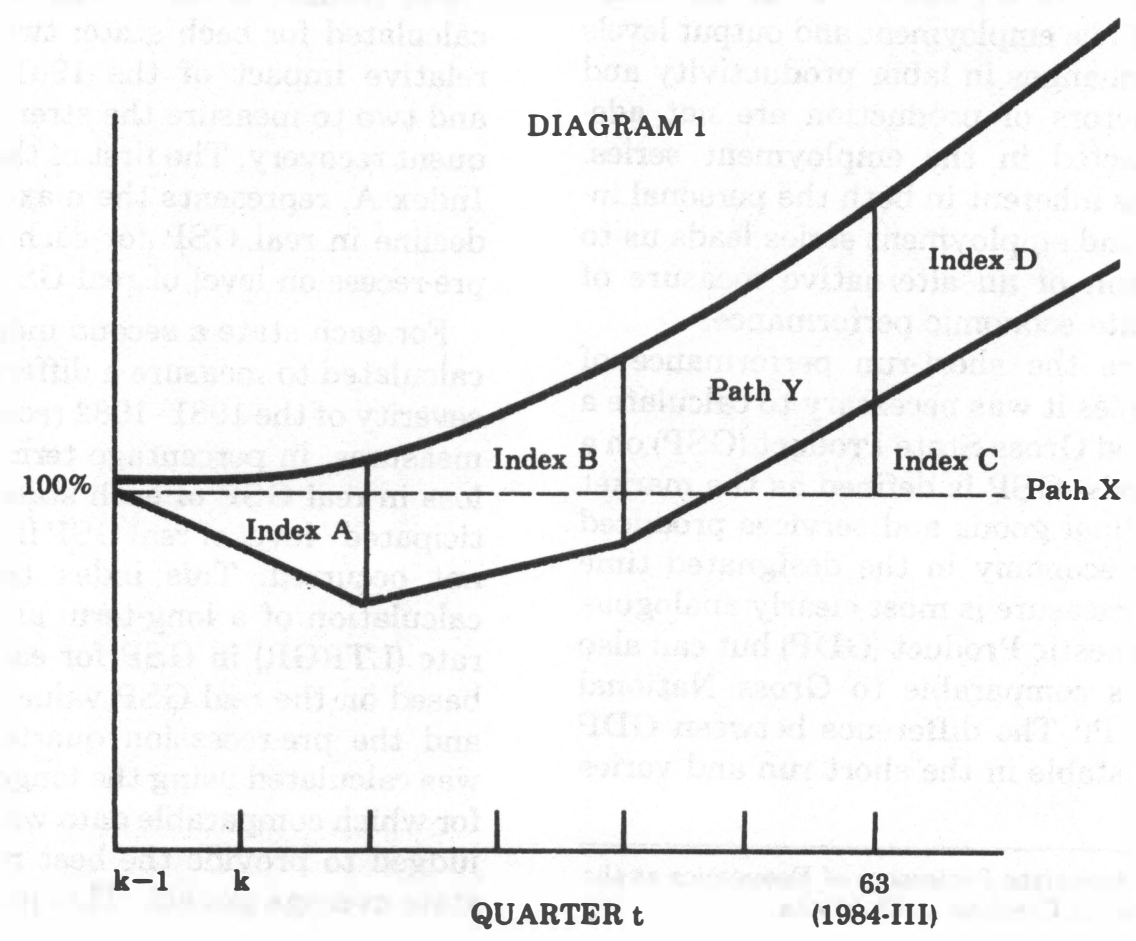




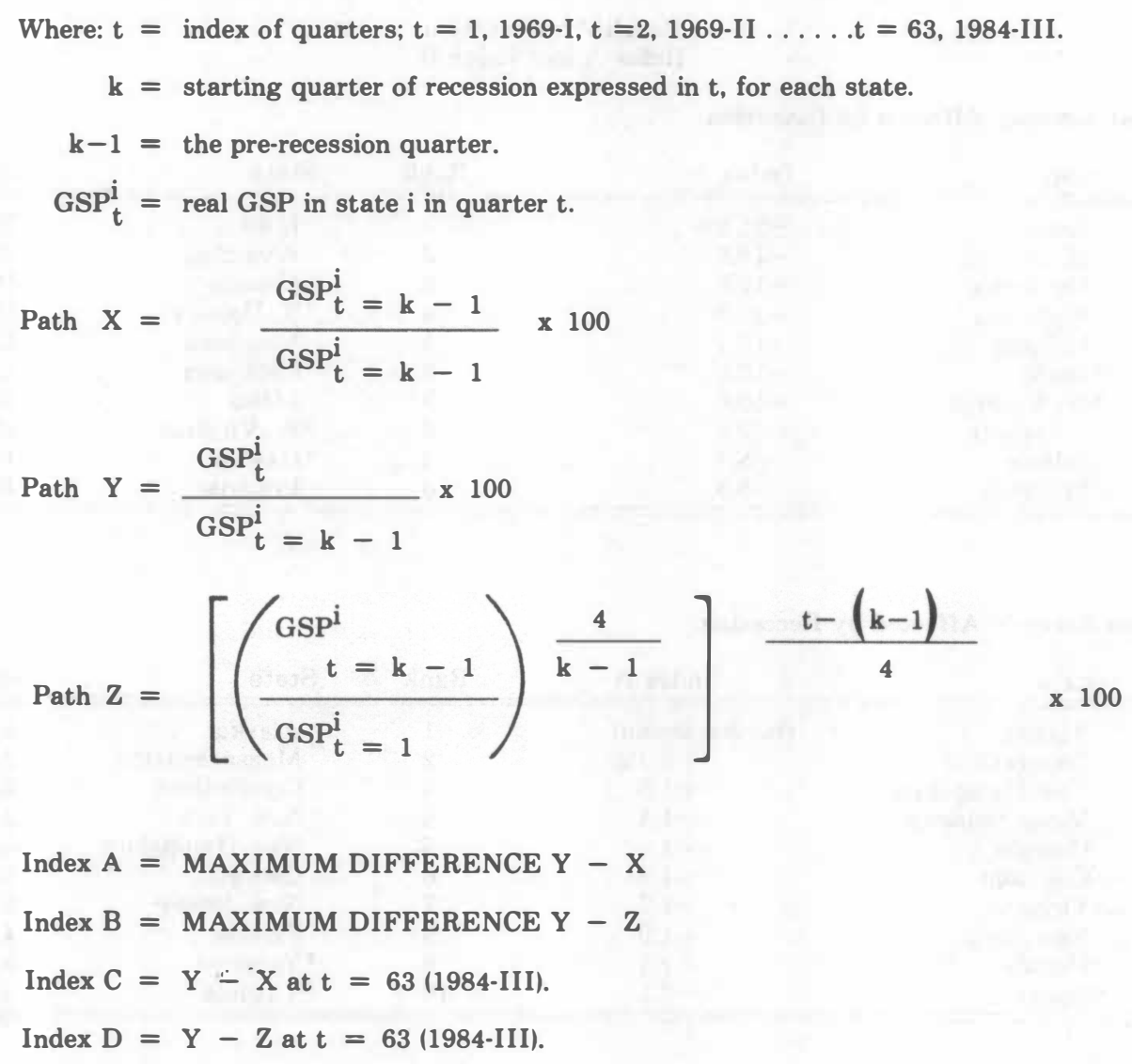

real GSP forward to 1984-III using the LTRGR. A negative value for this index will indicate that as of 1984-III, the state's output level had not yet reached the level of anticipated real GSP based on that state's LTRGR. A positive value for this index would indicate the state's economy had expanded beyond the anticipated level of real GSP projected for 1984-III.

Diagram 1 provides a schematic view of all four indices to be calculated for each state. In$\operatorname{dex} \mathrm{A}$ and Index $\mathrm{C}$ measure, in percentage terms, state performance relative to the pre-recession level of real GSP for that state. Index B and Index $D$ measure the performance of state economies relative to that state's anticipated real GSP, where anticipated real GSP is calculated for each state based on that state's pre-recession level of real GSP and LTRGR.

\section{Results: Recession}

Table 1 presents the rank ordered values of Index $A$ and Index $B$ for the 10 states most severely affected by the recession, as measured by the index value. Table 1 also contains the rank ordered index values for the 10 states least affected by the recession and values for Index $A$ and Index B for the United States economy as a whole. Complete results for all 50 states are presented in Appendix II, along with other detailed information related to the calculation of Index A and Index B.

Index $A$ measures, in percentage terms, the most severe decline in real GSP experienced by each state versus its pre-recession real GSP level. Iowa had by far the most serious decline in state output with a 25.2 percent drop versus its pre-recession level. Note that no "sunbelt" states appear in the list of 10 most severely affected states, as measured by Index A. " The dominance of farming and mining states in the list of those most severely affected was also striking.

Alaska was the state least affected by the recession; in fact, there was no decline in real GSP in Alaska over the relevant time period. Of the other states least affected by the reces- 
Table 1

Results**: Recession Index $A$ and Index $B$

States Most Severely Affected by Recession:

\begin{tabular}{rllccc} 
Rank & State & Index A & Rank & State & Index B \\
\hline \hline 1 & Iowa & $-25.2 \%$ & 1 & Iowa & $-29.3 \%$ \\
2 & N. Dakota & -13.5 & 2 & Wyoming & -25.4 \\
3 & Nebraska & -12.8 & 3 & Nevada & -18.2 \\
4 & Wyoming & -12.0 & 4 & N. Dakota & -18.0 \\
5 & Indiana & -10.7 & 5 & Nebraska & -17.6 \\
6 & *Idaho & -10.0 & 6 & Louisiana & -15.4 \\
7 & *W. Virginia & -10.0 & 7 & Idaho & -14.4 \\
8 & S. Dakota & -9.6 & 8 & *W. Virginia & -13.7 \\
9 & Illinois & -8.7 & 9 & *Hawaii & -13.7 \\
10 & Montana & -8.5 & 10 & Indiana & -13.1 \\
\hline \hline
\end{tabular}

States Least Severely Affected by Recession:

\begin{tabular}{rlcccc} 
Rank & State & Index A & Rank & State & Index B \\
\hline \hline 1 & Alaska & (No Recession) & 1 & Alaska & $-1.7 \%$ \\
2 & Connecticut & $-0.7 \%$ & 2 & Massachusetts & -2.0 \\
3 & New Hampshire & -1.0 & 3 & Connecticut & -2.6 \\
4 & Massachusetts & -1.1 & 4 & New York & -2.7 \\
5 & Georgia & -1.2 & 5 & New Hampshire & -3.5 \\
6 & Colorado & -1.3 & 6 & Georgia & -4.4 \\
7 & Virginia & -1.7 & 7 & New Jersey & -4.6 \\
8 & New York & -1.9 & 8 & Florida & -4.9 \\
9 & *Florida & -2.1 & 9 & *Vermont & -5.0 \\
10 & *Texas & -2.1 & 10 & *Virginia & -5.0 \\
\hline \hline
\end{tabular}

sion, roughly half are "sunbelt" states and half are "frostbelt" states. While Alaska's strong performance may be treated as a special case, the presence of Connecticut, New Hampshire, Massachusetts and New York in the list of least severely affected states strongly indicates the danger associated with concluding "frostbelt" states were uniformly harder hit by the recession than "sunbelt" states.

Index B measures the difference, in percentage terms, of actual state performance against that state's anticipated (non-recession) real GSP. Although in general there is consistency in the results, there are some notable differences in the Index $B$ results versus the In$\operatorname{dex} A$ results. Using Index $B$, Iowa again ranks as the state most severely affected by the recession, with actual real GSP differing by 29.2 percent from anticipated real GSP (when both GSP levels are measured against the prerecession level of real GSP). Wyoming shows an Index B value of -25.4 percent, more than double the percentage loss in output indicated by an Index $A$ value of -12.0 percent. This large increase in index value is attributable to the high long-term real growth rate $(6.28$ percent) calculated for Wyoming over the prerecession base period. Notable additions to the list of 10 most severely affected states are Nevada, Louisiana, and Hawaii.

Using Index B, Alaska is again the least affected by the recession with an index value of -1.7 percent. This negative value indicates that even though Alaska did not experience a drop in real GSP, its output level did fall short of its long-term average growth path during the relevant period. Using Index B, six of the 10 states least severely affected by the reces- 
sion were "frostbelt" states, again indicating there was no simple "sunbelt"/ "frostbelt" pattern in the severity of the recession.

A rank-correlation coefficient of .864 (significant at $\alpha=0.01$ ) was calculated between Index $A$ and Index B. This suggests in both the absolute measure (Index A) and the relative measure (Index B) of recession performance that the ordinal ranking of states is quite similar. Both the values for Index A and Index B and the consistency of state rankings between Index A and Index B indicate the great disparity in the impact of the recession between the states. The question of how strongly the states have recovered from the recession is addressed in the next section of the paper.

\section{Results: Recovery}

Table 2 presents the rank ordered values for Index $\mathrm{C}$ and Index $\mathrm{D}$ for the 10 states with the weakest recovery and the 10 states with the strongest recovery as of 1984-III. Index C and Index D values for all 50 states are presented in Appendix Three.

Index $\mathrm{C}$ measures, in percentage terms, the difference in real GSP in 1984-III versus the pre-recession level of real GSP for that state. Of the states with the weakest recovery, seven had not yet attained pre-recession output levels; this is indicated by their negative index values. Iowa's 1984-III output level was 8.2 percent below its pre-recession output level. Nine of the 10 states listed with weakest recoveries were listed as farthest below their long term anticipated output as measured by Index B in Table 1. Not surprisingly the states most severely affected by the recession have been the slowest to recover.

Measured by Index $\mathrm{C}$, the 10 states showing the strongest recovery are led by Alaska with a 20.3 percent increase in real GSP and New

Table 2

Results**: Recovery (as of 1984-III) Index $\mathrm{C}$ and Index $\mathrm{D}$

Weakest State Recovery:

\begin{tabular}{rlcccc} 
Rank & State & Index C & Rank & State & Index D \\
\hline \hline 1 & Iowa & $-8.2 \%$ & 1 & Wyoming & $-25.4 \%$ \\
2 & Wyoming & -5.4 & 2 & Nevada & -18.2 \\
3 & Montana & -3.5 & 3 & Iowa & -16.6 \\
$\mathbf{4}$ & W. Virginia & -2.4 & 4 & Louisiana & -15.5 \\
5 & Louisiana & -1.4 & 5 & Hawaii & -13.7 \\
6 & Nebraska & -1.3 & 6 & *Idaho & -13.6 \\
7 & Hawaii & -0.8 & 7 & *N. Dakota & -13.6 \\
8 & Idaho & 0.4 & 8 & Montana & -11.7 \\
9 & N. Dakota & 0.7 & 9 & Nebraska & -11.2 \\
10 & Nevada & 0.8 & 10 & W. Virginia & -10.0 \\
\hline \hline
\end{tabular}

Strongest State Recovery:

\begin{tabular}{rlcccc} 
Rank & State & Index C & Rank & State & Index D \\
\hline \hline 1 & Alaska & $20.3 \%$ & 1 & Massachusetts & $8.0 \%$ \\
2 & New Hampshire & 19.7 & 2 & New Hampshire & 7.8 \\
3 & Georgia & 17.5 & 3 & Connecticut & 6.0 \\
4 & Florida & 15.1 & 4 & Georgia & 5.2 \\
5 & Connecticut & 13.9 & 5 & New York & 4.9 \\
6 & Massachusetts & 13.4 & 6 & New Jersey & 4.4 \\
7 & Arizona & 12.7 & 7 & Rhode Island & 3.9 \\
8 & New Jersey & 12.0 & 8 & Michigan & 3.7 \\
9 & *Vermont & 11.4 & 9 & Vermont & 3.6 \\
10 & *Virginia & 11.4 & 10 & Maine & 1.3 \\
\hline \hline
\end{tabular}

U.S. Values:

Index $\mathrm{C}=8.1 \%$

Index $\mathrm{D}=-0.4 \%$

*Indicates tie in ranking.

** Complete results for all 50 states are presented in Appendix Three. 
Hampshire with a 19.7 percent increase. Nine of the 10 states listed with strongest recoveries, measured by Index C, were listed in Table 1 as least affected by the recession using Index B. The states least severely affected by the recession have shown the strongest recovery.

Index D measures the anticipated level of 1984-III (non-recession) output subtracted from the actual level of 1984-III real GSP as a percentage of the pre-recession level of real GSP for each state. Using the measure, Wyoming has had the weakest recovery with an index value of -25.4 percent. All 10 of the states with the weakest recovery, as measured by Index D, are still significantly below their prerecession long-term growth path for 1984-III.

The 10 states with the strongest recovery, as measured by Index D, are all above their prerecession long-term growth path for 1984-III. This group of states is led by Massachusetts with an index value of +8.0 percent. What is most striking in this list of the 10 states with the strongest recovery versus their long-term trend is the dominance of Northeastern states. All six New England states, along with New York and New Jersey, rank in the 10 states with the strongest recovery as measured by Index D. A rank-correlation coefficient of .751 (significant at $\alpha=.01$ ) was calculated between Index $\mathrm{C}$ and Index D. As was the case during recession, this coefficient suggests that in both an absolute measure (Index C) of recovery performance and a relative measure (Index D) of recovery performance, the ordinal ranking of states is quite consistent. The uniformity of the strength in these Northeastern states may suggest a change in their long-term growth rates versus the pre-recession period.

Two additional rank-correlation coefficients were calculated to compare state performance from recession to recovery using the absolute performance measures, Index A (recession) and Index $C$ (recovery) and the relative performance measures, Index $\mathrm{B}$ (recession) and Index D (recovery). The rank order for Index A and Index $B$ was the worst performing state during the recession being ranked first. For Index $C$ and In$\operatorname{dex} \mathrm{D}$, the state recording the weakest recovery was ranked first. The absolute rank-correlation coefficient (A-C) was .865 (significant at $\alpha=.01$ ) while the relative rank-correlation coefficient (B-D) was .833 (significant at $\alpha=.01$ ).

The high degree of rank-correlation in both measures provides strong evidence to dispel the myth that some states experience a hard or deep "V" cycle; that is, the generally held belief that states that experience a sharp decline during a recession will typically experience a strong recovery. The rationale is that some state economies have economic structures that lend themselves to volatile cyclical performance and what makes them weak in recession allows them to experience a strong recovery. However, with significant rank-correlation coefficients of .865 (absolute) and .833 (relative) between recession and recovery, it appears that states with the deepest recessions have generally had the weakest recoveries.

\section{Conclusions}

Two general conclusions can be drawn from the results of this study. First, that there has been a significant disparity regarding the impact of the recession and recovery on the different state economies; and second, that there is a consistency in the ordinal ranking of states experiencing the worst recession and the weakest recoveries.

An examination of the disparity in the impact of the recession on the different state economies shows that Iowa had the largest decrease in real GSP (more than 25 percent), while Alaska had no decrease at all. "Sunbelt" states in general were less severely affected by the recession. But many "frostbelt" states (such as Massachusetts, Connecticut, New Hampshire, and New York) were among the states least affected by the recession. The importance of agricultural and/or mining interests in the states most severely affected by the recession is striking.

The disparity in the recovery performance of the state economies is also tremendous. Seven states (Iowa, Wyoming, Montana, West Virginia, Louisiana, Nebraska, and Hawaii) had not returned to their pre-recession output levels by 1984-III. In contrast to those states with the weakest recoveries were states like Alaska, New Hampshire, Georgia, and Florida that had reached output levels more than 15 percent above their pre-recession levels by 1984-III. The most striking regional feature of the recovery is the uniform strength of the New England states which, along with New York and New Jersey, were substantially above their long-term growth paths in 1984-III. 
The disparity in state performances during the 1981-1982 recession and subsequent recovery is substantial and consistent. The information contained in this paper will be useful to those concerned with the impact of the most recent business cycle on state and regional economies. The states hardest hit by the recession have been the slowest to recover and this may have immediate policy implications. Future analysis of the structure of state economies and the performance of different industries within states over the business cycle could provide additional information not contained in this study.

\section{FOOTNOTES}

'GDP is the gross market value of the goods and services attributable to labor and property located in the United States. It equals GNP less the net inflow of labor and property incomes from abroad.

2For a detailed discussion of the benefits and problems associated with calculating GSP, see Kendrick and Jaycox (1965), Niemi (1972 and 1975), and L'Esperance, et. al. (1969 and 1974).
The choice of this base period was made to recognize the variability in the timing of state business cycles and retain the ability of the performance measures to reflect the short-term fluctuations of state output.

"Appendix II reveals that the largest drop in real GSP. Index A, for a "sunbelt" state was a 6.7 percent decline in Oklahoma followed by a 6.5 percent decline in Nevada.

\section{REFERENCES}

Kendrick, John W. and C. Milton Jaycox. "The Concept and Estimation of Gross State Products." Southern Economic Journal, 32 (1965) 153-168.

L'Esperance, Wilford L. and Daniel Fromm. "A Note on Estimating Gross State Product." Growth and Change, 5 (1974) 46-47.

L'Esperance, Wilford L. Gilbert Nestle and Daniel Fromm. "Gross State Product and an Econometric Model of a State." Journal of the American Statistical Association, 64 (1969) 787-807.

Niemi, Albert W., Jr. Gross Stave Product and Productivity in the Southeast. Chapel Hill: The University of North Carolina Press, 1975.

Niemi, Albert W., Jr. "A Re-examination of the KendrickJaycox Method of Estimating GSP." Review of Regional Studies, 2 (1972) 123-131.

\section{Appendix I}

Quarterly GSP is calculated by using equation (1) in section (A) below. The estimates employ quarterly industry data for state and national earnings and national income. To use equation (1), quarterly industry specific estimates must be made for capital consumption allowances (CCA), indirect business taxes (IBT), and price indices from annual industry specific data. The techniques for calculating CCA and IBT are fairly straightforward and are shown in section (B) below. The technique for calculating quarterly industry price indices is explained in section (C).

(A) Computation Technique and Data Sources for Quarterly GSP

(1) $\operatorname{RGSP}_{S}^{Q}=\sum_{i=1}^{11} \operatorname{RGSP}_{\mathrm{S}}^{\mathrm{Q}}$

and,

(2) $\operatorname{RGSP}_{s}^{\mathrm{iQ}}=\left(\begin{array}{c}\mathrm{E}^{\mathrm{iQ}} \\ \frac{\mathrm{S}}{\mathrm{E}_{\mathrm{US}}^{\mathrm{iQ}}}\end{array}\right)$

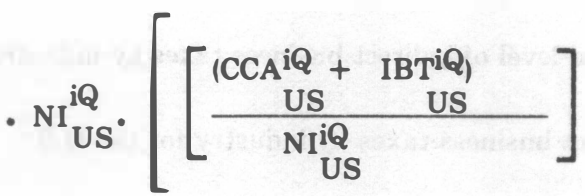

$+1] \cdot\left(\frac{\mathrm{PI}^{\mathrm{i}}}{{ }^{1972}}\right)$

where:

$\operatorname{RGSP}_{\mathbf{S}}^{\mathbf{Q}}=$ Annaulized real GSP in state $s$ in Quarter $\mathbf{Q}$.

$\operatorname{RGSP}_{\mathrm{S}}^{\mathrm{iQ}}=$ Annualized real output in sector $\mathrm{i}$ in state $s$ in the designated quarter.

$\mathrm{E}_{s}^{\mathrm{iQ}}=$ Annualized earnings in sector $\mathrm{i}$ in state $\mathrm{s}$ in the designated quarter: BEA TABLE 2-A (UNPUBLISHED). $\mathrm{E}_{\mathrm{US}}^{\mathrm{iQ}}=\begin{aligned} & \text { Annualized earnings in sector } \mathrm{i} \text { in the U.S. in the designated quarter: BEA TABLE 2-A (UN. } \\ & \text { PUBLISHED.) }\end{aligned}$

$\mathrm{NI}_{\mathrm{US}}^{\mathrm{iQ}}=$ Annualized national income without capital consumption adjustment from sector i for the U.S. in the designated quarter: BEA TABLE 6-4 National Income and Product Accounts (PUBLISHED).

$\mathrm{CCA}_{\mathrm{US}}^{\mathrm{iQ}}=$ Annualized quarterly capital consumption allowance by industry for the U.S.

$\mathrm{IBT}_{\mathrm{US}}^{\mathrm{iQ}}=$ Annualized indirect business taxes by industry for the U.S.

s $=$ state. 
$\mathrm{i}=$ industry (Eleven industry groups were used in this study. They included: (1) farm-agricultural services-forest-fisheries; (2) mining; (3) construction; (4) durable manufacturing; (5) non-durable manufacturing; (6) transportation-communications-public utilities; (7) wholesale trade: (8) retail trade; (9) finance-insurance-real estate; (10) servcies; and (11) government-government enterprises).

$\mathrm{PI}_{1972}^{\mathrm{i}}=$ Price index for industry $\mathrm{i}$ in base year 1972 for the U.S.

$P I^{i Q}=$ Price index for industry $i$ in the designated quarter for the U.S.

(B) Technique for Calculating Quarterly CCA and IBT

(3) $\mathrm{CCA}_{U S}^{\mathrm{iQ}}=\frac{\mathrm{CCA}^{\mathrm{i}} \mathrm{US}^{\mathrm{U}}}{\left(\mathrm{CCA}_{U S}^{\mathrm{t}}-\mathrm{A}_{\mathrm{US}}^{\prime}\right)} \cdot\left(\mathrm{CCA}^{\mathrm{tQ}}-\mathrm{AS}\right)^{\prime} \mathrm{US}^{\prime}$

where:

$\mathrm{CCA}_{\mathrm{US}}^{\mathrm{iQ}}=$ The annaualized quarterly level of capital consumption allowance for industry $\mathrm{i}$ in the U.S.

$\mathrm{CCA}_{U S}^{\mathrm{i}}=$ The annual capital consumption allowance for industry $\mathrm{i}$ in the U.S.

$\mathrm{CCA}_{\text {US }}^{\mathrm{t}}=$ The annual level of total capital consumption allowance for the U.S.

$A_{U S}=$ The annual capital consumption adjustment for buildings and equipment owned and used by nonprofit institutions serving individuals.

$\mathrm{CCA}_{\text {US }}^{\mathrm{tQ}}=$ The annualized quarterly total capital consumption allowance for the U.S.

(4) $\mathrm{IBT}_{U S}^{\mathrm{iQ}}=\frac{{ }_{U S}^{\mathrm{IBT}} \mathrm{US}_{\mathrm{US}}^{\mathrm{i}}}{\mathrm{IBT}_{\mathrm{US}}^{\mathrm{t}}} \cdot \mathrm{IBT}_{\mathrm{US}}^{\mathrm{tQ}}$

where:

${ }^{\mathrm{IBT}^{\mathrm{iQ}}}{ }_{\mathrm{US}}^{\mathrm{i}}=$ The annualized level of indirect business taxes by industry in a given quarter for the U.S.

$\mathrm{IBT}_{\text {US }}^{\mathrm{i}}=$ Annual indirect business taxes by industry for the U.S.

$\mathrm{IBT}_{\mathrm{US}}^{\mathrm{t}}=$ Annual total indirect business taxes for the U.S.

${ }_{\text {IBT }}^{\mathrm{tQ}}=$ TS $=$ Total annualized indirect business taxes for the U.S. in a given quarter.

(C) Quarterizing Technique for Industry Price Indices

A straightforward interpolation technique is applied for estimating the quarterly industry price indices. Annual industry price indices are inserted between the second and third quarters and a straight linear interpolation is performed to provide quarterly estimates.

Using the techniques outlined above in A, B, and C, estimates of annualized rates of real GSP were made for each state for each quarter under study. 


\section{Appendix II}

Results: Recession

Index $A$ and Index $B$

\begin{tabular}{|c|c|c|c|c|c|c|c|}
\hline State & $\begin{array}{l}\text { Pre-Recession } \\
\text { Quarter }\end{array}$ & $\begin{array}{l}\text { Pre-Recession } \\
\text { Real GSP In } \\
\text { Thousand } \$\end{array}$ & $\begin{array}{c}\text { Long-Term } \\
\text { Real Growth } \\
\text { Rate (LTRGR) } \\
\end{array}$ & $\begin{array}{c}\text { Index } \\
\mathrm{A}\end{array}$ & $\begin{array}{l}\text { Index A } \\
\text { Measurement } \\
\text { Quarter } \\
\end{array}$ & $\begin{array}{c}\text { Index } \\
\mathrm{B}\end{array}$ & $\begin{array}{l}\text { Index B } \\
\text { Measurement } \\
\text { Quarter }\end{array}$ \\
\hline Alabama & 1981-III & 19982185 & .0344 & $-5.6 \%$ & 1982-IV & $-9.9 \%$ & 1982-IV \\
\hline Alaska & 1981-III & 4539393 & .0677 & No Rec. & & $-1.7 \%$ & 1984-II \\
\hline Arizona & 1981-III & 16178080 & .0583 & $-5.2 \%$ & 1982-IV & $-12.5 \%$ & 1982-IV \\
\hline Arkansas & 1981-III & 11130252 & .0396 & $-5.3 \%$ & 1982-III & $-9.3 \%$ & 1982-III \\
\hline California & 1981-III & 182597254 & .0343 & $-3.3 \%$ & 1982-II & $-7.3 \%$ & 1982-IV \\
\hline Colorado & 1981-IV & 22402825 & .0573 & $-1.3 \%$ & 1982-II-III & $-6.5 \%$ & 1984-III \\
\hline Connecticut & 1981-III & 25567136 & .0255 & $-0.7 \%$ & 1982-II & $-2.6 \%$ & 1982-II \\
\hline Delaware & 1981-III & 4723653 & .0282 & $-3.2 \%$ & 1981-IV & $-9.9 \%$ & 1981-IV \\
\hline Florida & 1981-IV & 57357410 & .0521 & $-2.1 \%$ & 1982-II & $-4.9 \%$ & 1982-IV \\
\hline Georgia & 1981-III & 34384704 & .0395 & $-1.2 \%$ & 1981-IV & $-4.5 \%$ & 1982-III \\
\hline Hawaii & 1981-I & 2059142 & .0353 & $-5.7 \%$ & 1982-II & $-13.7 \%$ & 1984-III \\
\hline Idaho & 1981-III & 5302579 & .0446 & $-10.0 \%$ & 1982-III & $-14.4 \%$ & 1982-III-IV \\
\hline Illinois & 1981-III & 85238860 & .0167 & $-8.7 \%$ & 1983-I & $-11.2 \%$ & 1983-I \\
\hline Indiana & 1981-III & 33862237 & .0167 & $-10.7 \%$ & 1983-I & $-13.1 \%$ & 1983-I \\
\hline Iowa & 1981-III & 19338233 & .0273 & $-25.2 \%$ & 1983-I & $-29.3 \%$ & 1983-I \\
\hline Kansas & 1981-III & 15919689 & .0360 & $-5.6 \%$ & 1983-I & $-10.9 \%$ & 1983-I \\
\hline Kentucky & 1981-III & 19339717 & .0275 & $-6.6 \%$ & 1983-I & $-10.8 \%$ & 1983-I \\
\hline Louisiana & 1981-III & 26099811 & .0448 & $-5.9 \%$ & 1982-IV & $-15.4 \%$ & 1984-III \\
\hline Maine & 1981-III & 5853474 & .0281 & $-3.7 \%$ & 1983-I & $-5.1 \%$ & 1982-I \\
\hline Maryland & 1981-III & 26528312 & .0253 & $-4.2 \%$ & 1982-II & $-7.4 \%$ & 1983-I \\
\hline Massachusetts & 1981-IV & 41366921 & .0196 & $-1.1 \%$ & 1982-I & $-2.0 \%$ & 1982-II \\
\hline Michigan & 1981-IV & 56807133 & .0158 & $-7.9 \%$ & 1982-IV & $-9.4 \%$ & 1982-IV \\
\hline Minnesota & 1981-III & 29445767 & .0317 & $-5.9 \%$ & 1983-I & $-10.7 \%$ & 1983-I \\
\hline Mississippi & 1981-I & 11143941 & .0335 & $-4.9 \%$ & 1983-I & $-11.7 \%$ & 1983-I \\
\hline Missouri & 1981-III & 31760113 & .0199 & $-5.2 \%$ & 1983-I & $-8.2 \%$ & 1983-I \\
\hline Montana & 1981-III & 4225482 & .0267 & $-8.5 \%$ & 1983-I & $-12.7 \%$ & 1983-I \\
\hline Nebraska & 1981-III & 105957769 & .0321 & $-12.8 \%$ & 1983-I & $-17.6 \%$ & 1983-I \\
\hline Nevada & 1981-III & 5908443 & .0599 & $-6.5 \%$ & 1983-I & $-18.2 \%$ & 1984-III \\
\hline New Hampshire & 1981-IV & 5520545 & .0417 & $-1.0 \%$ & 1982-I & $-3.5 \%$ & 1982-IV \\
\hline New Jersey & 1981-III & 53191892 & .0247 & $-2.3 \%$ & 1982-II & $-4.6 \%$ & 1982-IV \\
\hline New Mexico & 1981-IV & 6649070 & .0388 & $-2.3 \%$ & 1982-II & $-5.1 \%$ & 1983-I \\
\hline New York & 1981-III & 140761373 & .0010 & $-1.9 \%$ & 1982-II & $-2.7 \%$ & 1982-II \\
\hline N. Carolina & 1981-III & 35163421 & .0366 & $-4.5 \%$ & 1982-II & $-8.6 \%$ & 1982-IV \\
\hline N. Dakota & 1981-III & 4485667 & .0454 & $-13.5 \%$ & 1982-III & $-18.0 \%$ & 1982-III \\
\hline Ohio & 1981-III & 69449122 & .0138 & $-8.2 \%$ & 1983-I & $-10.3 \%$ & 1983-I \\
\hline Oklahoma & 1982-I & 19836895 & .0481 & $-6.7 \%$ & 1983-I & $-11.5 \%$ & 1983-I \\
\hline Oregon & 1981-IV & 15671617 & .0329 & $-5.9 \%$ & 1982-IV & $-9.2 \%$ & 1982-IV \\
\hline Pennsylvania & 1981-III & 75836727 & .0160 & $-6.8 \%$ & 1982-IV & $-8.7 \%$ & 1982-IV \\
\hline Rhode Island & 1981-III & 5684614 & .0157 & $-4.1 \%$ & 1982-II & $-5.3 \%$ & 1982-II \\
\hline S. Carolina & 1981-III & 17139678 & .0424 & $-4.8 \%$ & 1982-IV & $-10.5 \%$ & 1983-I \\
\hline S. Dakota & 1981-III & 3766617 & .0267 & $-9.6 \%$ & 1982-III & $-12.3 \%$ & 1982-III \\
\hline Tennessee & 1981-III & 26232079 & .0357 & $-5.1 \%$ & 1982-II & $-9.7 \%$ & 1983-I \\
\hline Texas & 1981-III & 105477558 & .0565 & $-2.1 \%$ & 1982-IV & $-9.7 \%$ & 1983-II \\
\hline Utah & 1981-III & 8000135 & .0463 & $-3.2 \%$ & 1982-II & $-8.9 \%$ & 1983-I \\
\hline Vermont & 1981-III & 2747228 & .0256 & $-2.6 \%$ & 1982-II & $-5.0 \%$ & 1982-IV \\
\hline Virginia & 1981-III & 33323898 & .0365 & $-1.7 \%$ & 1982-II & $-5.0 \%$ & 1982-IV \\
\hline Washington & 1981-I & 28918951 & .0334 & $-5.7 \%$ & 1982-IV & $-11.8 \%$ & 1983-III \\
\hline W. Virginia & 1981-III & 9375539 & .0246 & $-10.0 \%$ & $1983-I$ & $-13.7 \%$ & 1983-I \\
\hline Wisconsin & 1981-III & 30739867 & .0272 & $-5.8 \%$ & 1982-IV & $-9.2 \%$ & 1982-IV \\
\hline Wyoming & 1981-III & 3456673 & .0628 & $-12.0 \%$ & 1983-II & $-25.4 \%$ & 1984-III \\
\hline U.S. & 1981-III & 1522100000 & .0275 & $-3.0 \%$ & 1982-III & $-6.3 \%$ & 1982-IV \\
\hline
\end{tabular}


Appendix III

Results: Recovery (as of 1984-III)

Index $\mathbf{C}$ and Index $\mathbf{D}$

\begin{tabular}{|c|c|c|c|c|c|}
\hline State & $\begin{array}{c}\text { Index } \\
\mathbf{C}\end{array}$ & $\begin{array}{c}\text { Index } \\
\text { D }\end{array}$ & State & $\begin{array}{c}\text { Index } \\
\mathbf{C}\end{array}$ & $\begin{array}{c}\text { Index } \\
\text { D }\end{array}$ \\
\hline Alabama & $6.0 \%$ & $-4.7 \%$ & Montana & $-3.5 \%$ & $-11.7 \%$ \\
\hline Alaska & $20.3 \%$ & $-1.4 \%$ & Nebraska & $-1.3 \%$ & $-11.2 \%$ \\
\hline Arizona & $12.7 \%$ & $-5.8 \%$ & Nevada & $0.8 \%$ & $-18.2 \%$ \\
\hline Arkansas & $8.1 \%$ & $-4.3 \%$ & New Hampshire & $19.7 \%$ & $+7.8 \%$ \\
\hline California & $10.2 \%$ & $-0.4 \%$ & New Jersey & $12.0 \%$ & $+4.4 \%$ \\
\hline Colorado & $10.0 \%$ & $-6.5 \%$ & New Mexico & $10.3 \%$ & $-0.8 \%$ \\
\hline Connecticut & $13.9 \%$ & $+6.0 \%$ & New York & $7.0 \%$ & $+4.9 \%$ \\
\hline Delaware & $8.0 \%$ & $-0.7 \%$ & N. Carolina & $8.7 \%$ & $-2.7 \%$ \\
\hline Florida & $15.1 \%$ & $+0.1 \%$ & N. Dakota & $0.7 \%$ & $-13.6 \%$ \\
\hline Georgia & $17.5 \%$ & $+5.2 \%$ & Ohio & $2.5 \%$ & $-1.7 \%$ \\
\hline Hawaii & $-0.8 \%$ & $-13.7 \%$ & Oklahoma & $4.5 \%$ & $-8.0 \%$ \\
\hline Idaho & $0.4 \%$ & $-13.6 \%$ & Oregon & $4.0 \%$ & $-5.3 \%$ \\
\hline Illinois & $2.7 \%$ & $-2.4 \%$ & Pennsylvania & $2.0 \%$ & $-2.8 \%$ \\
\hline Indiana & $2.5 \%$ & $-2.5 \%$ & Rhode Island & $8.7 \%$ & $+3.9 \%$ \\
\hline Iowa & $-8.2 \%$ & $-16.6 \%$ & S. Carolina & $8.2 \%$ & $-5.0 \%$ \\
\hline Kansas & $9.9 \%$ & $-1.3 \%$ & S. Dakota & $3.0 \%$ & $-5.3 \%$ \\
\hline Kentucky & $7.2 \%$ & $-1.3 \%$ & Tennessee & $9.2 \%$ & $-1.9 \%$ \\
\hline Louisiana & $-1.4 \%$ & $-15.5 \%$ & Texas & $8.1 \%$ & $-9.9 \%$ \\
\hline Maine & $10.0 \%$ & $+1.3 \%$ & Utah & $10.3 \%$ & $-4.2 \%$ \\
\hline Maryland & $4.4 \%$ & $-3.4 \%$ & Vermont & $11.4 \%$ & $+3.6 \%$ \\
\hline Massachusetts & $13.4 \%$ & $+8.0 \%$ & Virginia & $11.4 \%$ & $+0.1 \%$ \\
\hline Michigan & $8.0 \%$ & $+3.7 \%$ & Washington & $2.4 \%$ & $-9.8 \%$ \\
\hline Minnesota & $8.1 \%$ & $-1.8 \%$ & W. Virginia & $-2.4 \%$ & $-10.0 \%$ \\
\hline Mississippi & $5.9 \%$ & $-6.3 \%$ & Wisconsin & $4.5 \%$ & $-3.9 \%$ \\
\hline \multirow[t]{2}{*}{ Missouri } & $6.3 \%$ & $+0.3 \%$ & Wyoming & $-5.4 \%$ & $-25.4 \%$ \\
\hline & & & U.S. & $8.1 \%$ & $-0.4 \%$ \\
\hline
\end{tabular}

